\title{
Mental Health Service Users Experiences of Medication Discontinuation: A Systematic Review of Qualitative Studies
}

\begin{abstract}
Background: The use of psychotropic medication is often the first line of treatment for people with mental distress. However, many service users discontinue their prescribed medication, and little is known about their experiences or the reasons why they choose to stop taking medication.

Aim: The aim of this review is to synthesize research literature focused on the experiences of people who decided to discontinue taking medication for their mental health problem.

Methods: A systematic review of qualitative studies was conducted. Data bases were searched for qualitative research which explored participants' motivations for discontinuing medication and their experiences of the process.

Results: Six themes were identified: 1) Taking medications: a loss of autonomy, 2) Discontinuing medication: a thought-out process, 3) Factors influencing the decision to discontinue medication, 4) Discontinuing medication: experiences of the process, 5) Outcomes of discontinuing medication, 6) Managing mental distress in the absence of medication.

Conclusion: Service providers need to be aware that for some service user's psychotropic medication is not deemed a suitable treatment approach. Those who wish to discontinue medication need to be supported in the context of positive, therapeutic risk where their mental and physical health can be monitored and the likelihood of success increased.
\end{abstract}

Keywords: systematic review, qualitative research, medication discontinuation, service user, mental health recovery

\section{Citation:}

Keogh B, Murphy E, Doyle L, Sheaf G, Watts M, Higgins A. (2021) Mental health service users experiences of medication discontinuation: a systematic review of qualitative studies. Journal of Mental Health. doi: 10.1080/09638237.2021.1922644

Contact: Brian Keogh keoghbj@tcd.ie 


\section{Introduction}

The use of psychotropic medications remains a central pillar of the treatment and management of mental distress (Sparks, 2016). Pharmacological treatments were introduced in the 1950's, with the discovery that chlorpromazine could induce a sense of indifference and relaxation in patients (Ramachandraiah et al., 2009). Since then a range of 'antipsychotic' and antidepressant medications have been developed and credited with revolutionising the psychiatric services, including the closure of large mental institutions and improving the lives of people who experience psychosis (Healy, 2016; Wunderink., 2019). These discoveries and claims cemented the dominance of the medical model in the treatment of mental distress (Walter, 2013). The introduction of a second waves of antipsychotics and antidepressants in the 1990's promised a decrease in the range of side effects which marred the first generation's success (Healy, 2016, Paris, 2010). Standardized clinical treatment guidelines generally recommend that people experiencing psychosis should be treated with antipsychotic medication in the acute phase as well as throughout the protracted phases of maintenance and recovery (see for example National Institute for Health and Care Excellence [NICE], 2014). In addition, standard treatment of depression continues to recommend treatment with anti-depressants such as the selective serotonin re-uptake inhibitors (SSRIs) along with psychosocial interventions (NICE, 2020).

The use of psychotropic medication is supported by the literature and many people experience benefits from taking these drugs through their control of distressing symptoms and experiences (Thompson et al., 2020; Read et al., 2020). A recent systematic review of qualitative studies conducted by Bjornestad et al. (2020) found that there was general satisfaction with the use of antipsychotics in the short and medium term, but there was less satisfaction with their use over the long term. It is unsurprising therefore that several studies have found high rates of discontinuation amongst people who have been prescribed long-term psychotropic medication (Cooper et al., 2019; Kreyenbuhl et al., 2011; Moisan \& Grégoire, 2010; Verdoux et al., 2017). Absence of choice and involvement of service users in decision making around how much and for how long one must take medication is also identified as a factor in discontinuation (Morant et al., 2018). Despite NICE guidelines encouraging shared decision making, when it comes to medication, the service user's voice is often overlooked (Morant et al., 2016), and in some cases service users' preferences are not only unheard but 
they feel they are coerced and that choice is denied (Morant et al., 2016; Harris et al., 2017; Morrison, 2012).

In reviewing the literature, qualitative reviews completed by Thompson et al. (2020) and Bjornestad et al. (2020) highlight the challenges of using antipsychotic medication over the long term. This has resulted in large-scale correlational studies that focus on identifying factors that are associated with non-adherence. These studies are often framed within a language of non-compliance, non-adherence and medication refusal (Flore et al., 2019; Ascher- Svanum et al., 2010; Moritz et al., 2013; Sapra et al., 2014), with a view to developing more robust medication adherence strategies. Rather than perceiving an individual's decision to discontinue medication as a rationally thought out personal choice, decisions to manage mental distress without medication tends to be viewed as a consequence of an individual's "lack of insight" into the nature of their problems (Bulow et al., 2016; Chakrabarti, 2014). In the context of the possibility of identifying pathways for recovery without medication (Steingard, 2019), and the current emphasis on service user involvement and co-production (Chambers et al. 2017; Health Service Executive, 2017; Clark, 2015) this bias is a concern. It is therefore important to review and provide a thematic analysis of qualitative studies that prioritize the service user's lived experience of the discontinuation decision making process and most significantly their experience of the actual discontinuation process. While some systematic reviews on service users' experiences of taking psychotropic medication could be located in the literature (e.g. Britten et al. 2010; Bjornestad et al. 2020; and Thompson et al. 2020), a review that explored experiences of the discontinuing psychotropic medication process could not be located. The aim of this review therefore is to synthesize peer reviewed published primary research literature focused on the lived experiences of people who made a decision to discontinue prescribed medication for their mental health problem.

\section{METHODS}

\section{Search strategy and data sources}

A systematic review and thematic analysis were undertaken. The three electronic databases most relevant to the research aim - CINAHL, MEDLINE and PsycINFO - were systematically searched from their foundation until January 2020 for peer reviewed, qualitative studies in the English language. The search strategy was developed by the project team which included support from a librarian with expertise in web-based information 
systems and systematic review methodologies. Our focus was on both diagnoses and medication use that was couched within the broad category of 'severe and enduring' mental health difficulties. Consequently, we focused on those medications that were commonly used long term such as antipsychotics, mood stabilisers and anti-depressants. Following an initial search, targeted searches using controlled vocabulary and title, abstract and keyword/contributed indexing fields were developed for the four key areas of 'mental illness', 'discontinuing', 'medications', and 'experience', combined with the Boolean operators 'AND' and 'OR' as appropriate. Reference lists of the most relevant papers were also reviewed for potentially eligible studies that may not have been captured by the electronic search strategy. An example search strategy in MEDLINE is available on request. An article was included when it satisfied the following eligibility criteria:

- Peer reviewed primary research articles about people's experiences stopping medication for their mental health difficulties.

- Qualitative research using any methodology

- Mixed methods designs that included a qualitative element

- Quantitative surveys that incorporated a qualitative component such as open-ended questions.

\section{Screening and selection process}

To assist with the screening and selection process, Covidence online software system (hhtps://covidence.org/) was used. Subsequent to the removal of all duplicates, a two-stage screening process was used to assess the relevance of research studies identified in the search. In the first stage of the screening process, only titles and abstracts were reviewed to exclude studies that did not fit the inclusion criteria. One project team member reviewed all titles and abstracts (xx) and then two project team members agreed upon the selection of studies for full-text retrieval (xx, xx). For the second stage, full-text articles were assessed by two team members independently $(\mathrm{xx}, \mathrm{xx})$ and eligible studies agreed upon for data extraction. Any disagreement about inclusion or exclusion that arose during the selection process was resolved through discussion with other team members.

\section{Appraisal of the evidence}

Once the papers for final inclusion were agreed upon, $(n=14)$ they were quality assessed using the validated critical appraisal skills programme (CASP) appraisal tool (http://www.casp-uk.net). The CASP is a 10-question checklist that reports on the quality of 
qualitative research. It assesses the following: the appropriateness of the methodology, recruitment strategy, data collection methods, data analysis processes, ethical considerations, research participant relationships, findings and value of the research overall. It is designed to allow reviewers assess each question selecting one of three answers (i.e. yes explicit=1, implicit $=0.5$, no, or can't tell $=0$ ). The maximum score achievable is 10 , with the overall quality rating divided into high (score of 8-10), medium (score of 5-7.5) and low 0-4.5). Two team members $(\mathrm{xx}, \mathrm{xx})$ conducted the quality assessment and the mean score for each paper was calculated. Where there was disagreement between reviewers, a third reviewer (xx) was consulted and consensus reached.

\section{Thematic analysis}

A thematic analysis was adopted using Braun and Clarke's (2006) approach. While the approach adopted was similar to the thematic synthesis described by Thomas and Harden (2008) we did not strive for analytical themes opting for descriptive themes which aligned with the review aims. A data extraction form was designed and secondary data pertinent to the review aims were extracted and coded. We conceptualized 'data' for the review as all of the text that was labelled as findings or results in the included papers. Following quality appraisal, data relevant to the review aims were extracted verbatim from the findings sections of the included papers (Thomas and Harden, 2008). This allowed for the descriptive analysis to be completed despite the variation in methodological approaches within the papers. The processes of data coding and the generation of themes did not deviate from Braun and Clarke's (2006) guidelines. Once codes were assigned, they were collated and sorted into potential themes which were refined until the final themes were identified and agreed on. While these are presented as a descriptive analysis based on the cumulative analysis of the data, the themes do contain some third order interpretations that go beyond a description of the findings of the original studies (Thomas and Harden, 2008). To enhance rigour, robustness and ensure consistency of the process, three project team members cross checked each data extraction $(\mathrm{xx}, \mathrm{xx}, \mathrm{xx})$, the coding process and the thematic analysis.

\section{Findings}

\section{Findings from the systematic searches}

In total fourteen $(\mathrm{n}=14)$ articles (Bjornestad et al., 2017; Boath et al., 2004; Bülow et al.. 2016; Cappleman et al., 2015; Fu et al., 2019; Gale et al., 2012; Givens et al., 2006; Katz et al., 2019; LeGeyt et al., 2017; Roe et al., 2009; Solomon \& Hamilton, 2013; Teferra et al., 2013; Tranulis et al., 2011; Zarea et al., 2016) were included in the review. The studies were conducted between 2004 and 2019 in a variety of countries (UK, Norway, Sweden, Israel, 
Iran, Ethiopia, Australia, Canada and USA). In total 336 participants were involved. Two studies (Teferra et al., $2013(\mathrm{n}=24)$ and Zarea et al., $2016(\mathrm{n}=5)$ do not report the participant's' gender. In total across the other studies there are more female $(n=190)$ participants than male $(n=137)$. Figure 1 presents a PRISMA diagram which details the search and selection process. An overview of the studies including their research aims, data collection methods and participant details is presented in table 1. Following application of the CASP, the quality rating of the articles ranged from medium to high and all were included in the subsequent data extraction and analysis (table 1). Seven of the papers scored within the medium range following quality appraisal (5.5 - 7.5), (Bülow et al., 2016; Cappleman et al., 2015; Givens et al., 2012; Roe et al., 2009, Salomon and Hamilton, 2013; Teferra et al., 2013; Zarea et al., 2016). The range in scoring related to inadequate reporting on research participant relationships such as the researchers not fully examining their own roles with the research or the potential for bias. In addition implications for practice or further research and ethical issues, beyond stating that ethical approval was achieved were not detailed in some of the papers. 
Figure 1: PRISMA flow diagram of study selection process

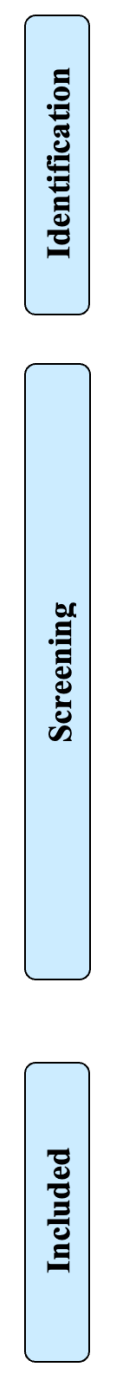
Records identified through database
searching $(\mathrm{n}=17,142)$
1610 duplicates removed

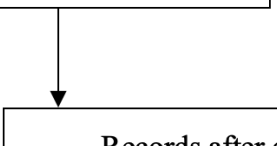

Records after duplicates removed $(\mathrm{n}=15,532)$

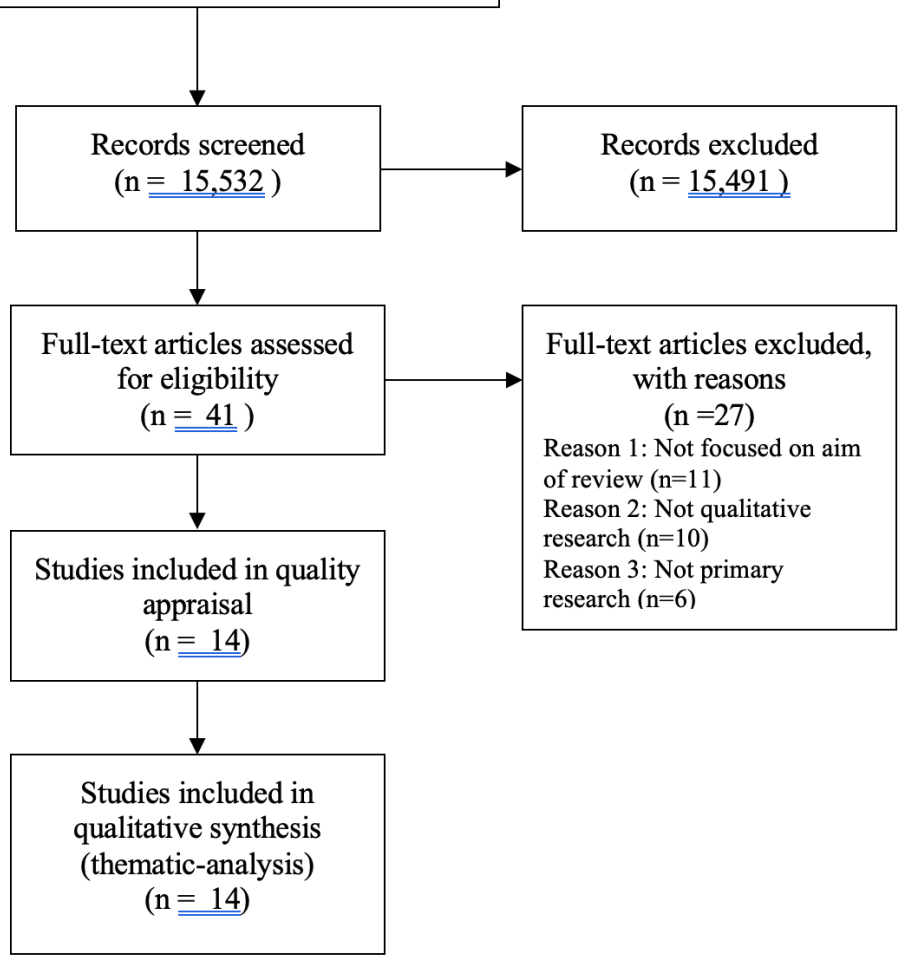




\begin{tabular}{|c|c|c|c|c|c|}
\hline $\begin{array}{c}\text { Author and } \\
\text { Year }\end{array}$ & Main Research Aim & $\begin{array}{c}\text { Research Design and } \\
\text { Data Collection } \\
\text { Methods }\end{array}$ & Participant Details & Country & $\begin{array}{c}\text { Quality } \\
\text { rating }\end{array}$ \\
\hline $\begin{array}{l}\text { Bjornestad et al } \\
(2017)\end{array}$ & $\begin{array}{l}\text { To investigate } \\
\text { experiences of clinically } \\
\text { recovered service users } \\
\text { of antipsychotic } \\
\text { medications during and } \\
\text { after a first episode of } \\
\text { psychosis. }\end{array}$ & $\begin{array}{l}\text { Design: Interpretive- } \\
\text { phenomenological } \\
\text { framework } \\
\text { Data Collection: } \\
\text { Individual Interviews } \\
\text { Sampling: Not stated } \\
\text { Length of interview: } \\
\text { 37-76 minutes }\end{array}$ & $\begin{array}{l}\text { Sample size: } \mathrm{N}=20 \\
\text { Gender: Female }(\mathrm{n}=10) \text {; Male } \\
(\mathrm{n}=10) ; \\
\text { Age: Range } 15-65 \\
\text { Sample details: Individuals } \\
\text { diagnosed with first episode } \\
\text { psychosis. } \\
\text { Medication details: Experiences of } \\
\text { taking antipsychotic medication. }\end{array}$ & Norway & $\begin{array}{l}8.5 \\
\text { High }\end{array}$ \\
\hline $\begin{array}{l}\begin{array}{l}\text { Boath et al. } \\
(2004)\end{array}\end{array}$ & 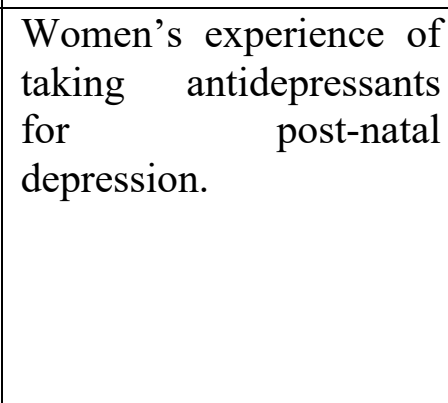 & $\begin{array}{l}\text { Design: Qualitative } \\
\text { design } \\
\text { Data Collection: Free } \\
\text { text responses as part of } \\
\text { a survey } \\
\text { Sampling: Purposive } \\
\text { Length of interview: } \\
\text { Not applicable }\end{array}$ & $\begin{array}{l}\text { Sample size: } \mathrm{N}=35 \\
\text { Gender: Female }(\mathrm{n}=35) \\
\text { Age: } 20 \text { - } 38 \\
\text { Sample details: Women with a } \\
\text { diagnosis of post-natal depression. } \\
\text { Medication details: Experiences of } \\
\text { taking antidepressant medication }\end{array}$ & UK & $\begin{array}{l}9 \\
\text { High }\end{array}$ \\
\hline $\begin{array}{l}\text { Bülow et al. } \\
(2016)\end{array}$ & $\begin{array}{l}\text { To investigate } \\
\text { individuals' experiences } \\
\text { of taking psychotropic } \\
\text { medications and how it } \\
\text { affected their lives }\end{array}$ & $\begin{array}{l}\text { Design: Qualitative } \\
\text { design } \\
\text { Data Collection: } \\
\text { Individual Interviews } \\
\text { Sampling: Convenience } \\
\text { sample } \\
\text { Length of interview: } \\
1.5-3 \text { hours }\end{array}$ & $\begin{array}{l}\text { Sample size: } \mathrm{N}=19 \\
\text { Gender: Female }(\mathrm{n}=10) \text {; Male } \\
(\mathrm{n}=9) ; \\
\text { Age: Range } 20-69 \text { years; median } \\
\text { age of } 41 \text { years. } \\
\text { Sample details: Individuals } \\
\text { diagnosed with psychosis }(\mathrm{n}=19) \text {. } \\
\text { Medication details: Length of time } \\
\text { taking medications not reported. }\end{array}$ & Sweden & $\begin{array}{l}7 \\
\text { Medium }\end{array}$ \\
\hline
\end{tabular}




\begin{tabular}{|c|c|c|c|c|c|}
\hline $\begin{array}{l}\text { Cappleman et al. } \\
\text { (2015) }\end{array}$ & $\begin{array}{l}\text { To explore the processes } \\
\text { by which people manage } \\
\text { bipolar moods without } \\
\text { medication. }\end{array}$ & $\begin{array}{l}\text { Design: Grounded } \\
\text { theory } \\
\text { Data Collection: } \\
\text { Individual Interviews } \\
\text { Sampling: Theoretical } \\
\text { Length of interview: } \\
\text { 160-105 minutes }\end{array}$ & $\begin{array}{l}\text { Sample size: } \mathrm{N}=9 \\
\text { Gender: Female }(\mathrm{n}=4) \text {; Male }(\mathrm{n}=5) \\
\text { Age: Range } 31-50 \text { years; Mean age } \\
36 \\
\text { Sample details: Individuals with a } \\
\text { diagnosis of bipolar disorder who } \\
\text { had used medication }(\mathrm{n}=9) \\
\text { Medication details: Mean time the } \\
\text { participants were off medication } \\
38.8 \text { months. }\end{array}$ & UK & $\begin{array}{l}8.5 \\
\text { High }\end{array}$ \\
\hline Fu et al (2019) & $\begin{array}{l}\text { This study examined the } \\
\text { development in } \\
\text { cognition, work, and } \\
\text { social } \\
\text { functioning in a group of } \\
\text { fully recovered } \\
\text { individual who had a } \\
\text { diagnosis of first- } \\
\text { episode schizophrenia. }\end{array}$ & $\begin{array}{l}\text { Design: Mixed methods } \\
\text { Data Collection: Semi } \\
\text { structured individual } \\
\text { Interviews } \\
\text { Sampling: Purposive } \\
\text { Length of interview: } \\
\text { Not reported. }\end{array}$ & 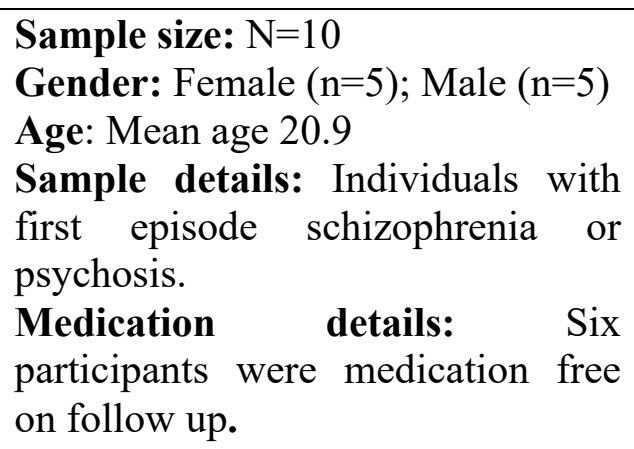 & Norway & $\begin{array}{l}7.5 \\
\text { Medium }\end{array}$ \\
\hline Gale et al. (2012) & $\begin{array}{l}\text { To undertake a service } \\
\text { user-led research study } \\
\text { to explore the experience } \\
\text { of mental health service } \\
\text { users when they decide } \\
\text { to either change or } \\
\text { terminate their } \\
\text { prescribed medication. }\end{array}$ & $\begin{array}{l}\text { Design: Qualitative } \\
\text { design } \\
\text { Data Collection: Focus } \\
\text { groups } \\
\text { Sampling: Convenience } \\
\text { sample } \\
\text { Length of interview: } \\
\text { Not reported. }\end{array}$ & 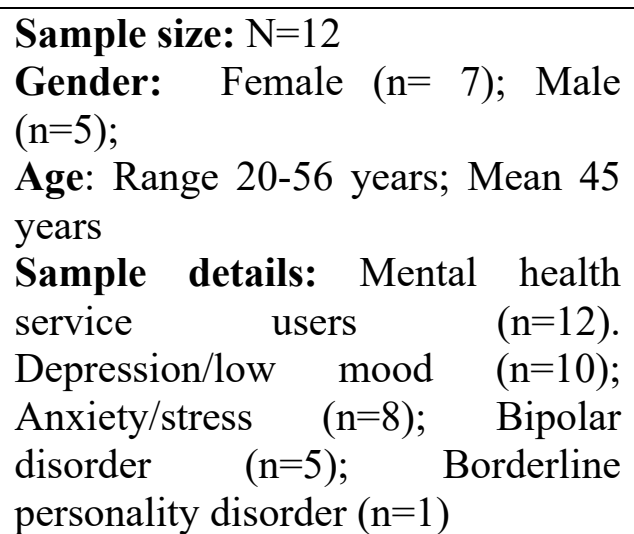 & UK & $\begin{array}{l}8.5 \\
\text { High }\end{array}$ \\
\hline
\end{tabular}




\begin{tabular}{|c|c|c|c|c|c|}
\hline & & & $\begin{array}{l}\text { Medication details: Participants } \\
\text { who had either changed or stopped } \\
\text { taking their mental health } \\
\text { medication. }\end{array}$ & & \\
\hline $\begin{array}{lll}\text { Givens } & \text { et } & \text { al. } \\
(2006) & & \end{array}$ & $\begin{array}{l}\text { To explore attitudes } \\
\text { toward antidepressants } \\
\text { in a sample of depressed, } \\
\text { community-dwelling } \\
\text { older people who were } \\
\text { offered treatment. }\end{array}$ & $\begin{array}{l}\text { Design: Qualitative } \\
\text { design } \\
\text { Data Collection: } \\
\text { Individual Interviews } \\
\text { Sampling: Purposive } \\
\text { Length of interview: } \\
\text { 60-90 minutes }\end{array}$ & $\begin{array}{l}\text { Sample size: } \mathrm{N}=68 \\
\text { Gender: Female }(\mathrm{n}=47) \text {; Male } \\
(\mathrm{n}=19) \text {; } \\
\text { Age: Range from } 60 \text { to over } 80 \\
\text { years. } \\
\text { Sample details: Older people who } \\
\text { experienced depression. } \\
\text { Medication details: older people } \\
\text { who had taken or were offered } \\
\text { anti-depressants. }\end{array}$ & USA & $\begin{array}{l}7.5 \\
\text { Medium }\end{array}$ \\
\hline Katz et al. (2019) & $\begin{array}{l}\text { Why and how did } \\
\text { participants choose to } \\
\text { discontinue taking } \\
\text { medication and what } \\
\text { were their experiences of } \\
\text { the process. }\end{array}$ & $\begin{array}{l}\text { Design: Narrative } \\
\text { approach. } \\
\text { Data Collection: } \\
\text { Individual Interviews } \\
\text { Sampling: Purposive } \\
\text { Length of interview: } 2 \\
\text { hours on average. }\end{array}$ & $\begin{array}{l}\text { Sample size: } \mathrm{N}=21 \\
\text { Gender: Female }(\mathrm{n}=12) \text {; Male } \\
(\mathrm{n}=9) \text {; } \\
\text { Age: Range from } 25 \text { to } 65 \text { years, } \\
\text { mean age } 38 \text {. } \\
\text { Sample details: The participant had } \\
\text { a range of psychiatric diagnoses. } \\
\text { Medication details: All participant } \\
\text { had been prescribed some form of } \\
\text { psychotropic medication but } 19 \\
\text { stated that they had stopped } \\
\text { completely. }\end{array}$ & Israel & $\begin{array}{l}9 \\
\text { High }\end{array}$ \\
\hline
\end{tabular}




\begin{tabular}{|c|c|c|c|c|c|}
\hline $\begin{array}{l}\text { Le Geyt et al. } \\
(2017)\end{array}$ & $\begin{array}{l}\text { To explore } r \text { personal } \\
\text { accounts of making } \\
\text { choices about taking } \\
\text { neuroleptics, rin } \\
\text { particular decisions } \\
\text { about stopping these } \\
\text { medications. r To } \\
\text { contribute to evidence } \\
\text { based guidance to } \\
\text { support prescribers and } \\
\text { service users making } \\
\text { choices about continuing } \\
\text { and discontinuing } \\
\text { medication. }\end{array}$ & $\begin{array}{l}\text { Design: Grounded } \\
\text { theory } \\
\text { Data Collection: } \\
\text { Individual Interviews } \\
\text { Sampling: Convenience } \\
\text { sample } \\
\text { Length of interview: } \\
\text { 48-120 minutes }\end{array}$ & $\begin{array}{l}\text { Sample size: } \mathrm{N}=12 \\
\text { Gender: Female }(\mathrm{n}=7) \text {; Male } \mathrm{n}=5) \\
\text { Age: Range } 21 \text { and } 60 \text { years. } \\
\text { Sample details: Participants were } \\
\text { taking medication for psychoses. } \\
\text { Medication details: Diverse } \\
\text { experiences of taking medication. } \\
\text { Duration of use between } 3 \text { months } \\
\text { and } 40 \text { years. }\end{array}$ & UK & $\begin{array}{l}9 \\
\text { High }\end{array}$ \\
\hline Roe et al. (2009) & $\begin{array}{l}\text { To explore why and how } \\
\text { people with a serious } \\
\text { mental illness (SMI) } \\
\text { choose to stop taking } \\
\text { prescribed medication. }\end{array}$ & $\begin{array}{l}\text { Design: Qualitative } \\
\text { design } \\
\text { Data Collection: } \\
\text { Individual Interviews } \\
\text { Sampling: Purposive } \\
\text { sample } \\
\text { Length of interview: } 90 \\
\text { minutes }\end{array}$ & $\begin{array}{l}\text { Sample size: } \mathrm{N}=7 \\
\text { Gender: Female ( } \mathrm{n}=4) \text {; Male } \\
(\mathrm{n}=3) \\
\text { Age: Not reported. } \\
\text { Sample details: Persons with } \\
\text { serious mental illness who had not } \\
\text { taken medication for at least a year } \\
(\mathrm{n}=7) \text {. Participants with a diagnosis } \\
\text { of schizophrenia spectrum disorder } \\
(\mathrm{n}=4 \text { : all Female) and bipolar } \\
\text { disorder ( } \mathrm{n}=3 \text { : All Male) } \\
\text { Medication details: Only those } \\
\text { who had fully discontinued taking } \\
\text { medication eligible to participate. }\end{array}$ & Israel & $\begin{array}{l}7.5 \\
\text { Medium }\end{array}$ \\
\hline
\end{tabular}




\begin{tabular}{|c|c|c|c|c|c|}
\hline $\begin{array}{l}\text { Salomon and } \\
\text { Hamilton (2013) }\end{array}$ & $\begin{array}{l}\text { First-hand experiences } \\
\text { of antipsychotic } \\
\text { discontinuation in an } \\
\text { Australian context (p. } \\
\text { 160). }\end{array}$ & $\begin{array}{l}\text { Design: Qualitative } \\
\text { design } \\
\text { Data Collection: Free } \\
\text { text responses as part of } \\
\text { a survey } \\
\text { Sampling: Convenience } \\
\text { sample } \\
\text { Length of interview: } \\
\text { Not applicable }\end{array}$ & $\begin{array}{l}\text { Sample size: } \mathrm{N}=98 \\
\text { Age: Mean age } 42 . \\
\text { Gender: Female }(\mathrm{n}=46) ; \text { male } \\
(\mathrm{n}=50), \quad \text { transgender }(\mathrm{n}=1) \text {; } \\
\text { undisclosed }(\mathrm{n}=1) \text {. } \\
\text { Sample details: People with } \\
\text { experience discontinuing } \\
\text { antipsychotic medication }(\mathrm{n}=98) \\
\text { Medication details: Details from } \\
\text { the survey available (Solomon et } \\
\text { al., 2014). }\end{array}$ & Australia & $\begin{array}{l}5.5 \\
\text { Medium }\end{array}$ \\
\hline $\begin{array}{l}\text { Teferra et al. } \\
(2013)\end{array}$ & $\begin{array}{l}\text { To explore the reasons } \\
\text { for low adherence to } \\
\text { medication in a rural } \\
\text { Ethiopian setting from } \\
\text { the perspectives of } \\
\text { people with } \\
\text { schizophrenia, their } \\
\text { caregivers, research field } \\
\text { workers and health } \\
\text { workers with a view to } \\
\text { informing interventions } \\
\text { to mitigate the problem. }\end{array}$ & $\begin{array}{l}\text { Design: } \\
\text { design } \\
\text { Data } \\
\text { Individual } \quad \text { Collection: } \\
\text { and focus groups } \\
\text { Sampling: Purposive } \\
\text { sample } \\
\text { Length of interview: } \\
\text { Not reported. }\end{array}$ & $\begin{array}{l}\text { Sample size: } \mathrm{N}=24 \\
\text { Age: not reported. } \\
\text { Gender: Not reported. } \\
\text { Sample details: Individuals who } \\
\text { had been prescribed antipsychotic } \\
\text { medication and who had a diagnosis } \\
\text { of schizophrenia. } \\
\text { Medication details: No details } \\
\text { provided. }\end{array}$ & Ethiopia & $\begin{array}{l}7 \\
\text { Medium }\end{array}$ \\
\hline $\begin{array}{l}\text { Tranulis et al } \\
(2011)\end{array}$ & $\begin{array}{lr}\text { To explore service users } \\
\text { perspectives } \\
\text { adherence } \\
\text { antipsychotics. }\end{array}$ & $\begin{array}{l}\text { Design: Qualitative } \\
\text { design. } \\
\text { Data Collection: Semi } \\
\text { structured interviews. } \\
\text { Sampling:Purposive } \\
\text { sample. } \\
\text { Length of interview: } \\
\text { Not reported. }\end{array}$ & $\begin{array}{l}\text { Sample size: } \mathrm{N}=20 \\
\text { Age: Meant age } 39 . \\
\text { Gender: Female }(\mathrm{n}=3) ; \text { Male } \\
(\mathrm{n}=17) \text {. } \\
\text { Sample details: fourteen of the } \\
\text { participants had a medical diagnosis } \\
\text { of schizophrenia and six had a } \\
\text { diagnosis of schizoaffective } \\
\text { disorder. }\end{array}$ & Canada & $\begin{array}{l}8 \\
\text { High }\end{array}$ \\
\hline
\end{tabular}




\begin{tabular}{|c|c|c|c|c|c|}
\hline & & & $\begin{array}{l}\text { Medication details: The } \\
\text { participants has been taking } \\
\text { medication from one to } 39 \text { years. }\end{array}$ & & \\
\hline Zarea et al (2016) & $\begin{array}{l}\text { To gain insight into the } \\
\text { experiences of patients, } \\
\text { their family members, } \\
\text { and nurses on the } \\
\text { medication adherence in } \\
\text { patients with severe and } \\
\text { chronic psychiatric } \\
\text { disorders in selected } \\
\text { hospitals in Ahvaz, Iran. }\end{array}$ & $\begin{array}{l}\text { Design: Qualitative } \\
\text { design } \\
\text { Data Collection: } \\
\text { Individual interviews } \\
\text { Sampling: Purposive } \\
\text { sample } \\
\text { Length of interview: } 30 \\
\text { - } 60 \text { minutes. }\end{array}$ & $\begin{array}{l}\text { Sample size: } \mathrm{N}=5 \\
\text { Age: Not reported. } \\
\text { Gender: Not reported. } \\
\text { Sample details: Persons with } \\
\text { 'chronic psychiatric disorder' } \\
\text { patients in a psychiatric hospital } \\
(\mathrm{n}=5) \\
\begin{array}{l}\text { Medication details: No details } \\
\text { provided. }\end{array}\end{array}$ & Iran & $\begin{array}{l}7 \\
\text { Medium }\end{array}$ \\
\hline
\end{tabular}

Table 1. Study aims, methodological characteristics and quality appraisal score of the included studies 


\section{Findings from the thematic analysis}

Following data extraction and analysis, six themes emerged from the extracted data:

(1) Taking medications: a loss of autonomy

(2) Discontinuing medication: a thought out process,

(3) Factors influencing the decision to come off medication,

(4) Discontinuing medication: experiences of the process,

(5) Outcomes of discontinuing medication,

(6) Managing mental distress in the absence of medication.

\section{Theme 1: Taking medication: a loss of autonomy}

For many of the participants, the process of being prescribed and taking medication was seen as an erosion of their personal autonomy, loss of control and for some taking medication conflicted with their personal beliefs about health and wellness (Bjornestad et al., 2017; Bülow et al., 2016; Katz et al., 2019; LeGeyt et al., 2017; Roe et al., 2009; Salomon \& Hamilton, 2013; Tranulis et al., 2011). Central to this experience was the perceived lack of collaboration between the participant and the prescribing professional and the limited choices that were available to them (Bülow et al., 2016; Gale et al., 2012; LeGeyt et al., 2017; Salomon \& Hamilton, 2013; Tranulis et al., 2011). In addition, there was a perceived lack of consideration by health service providers of their needs or preferences, with participants in one study feeling they were passive within the decision making process (Roe et al., 2009). Furthermore, in many cases participants reported a lack of information provision to enable them make an informed decision about whether or not to take medication (Bülow et al., 2016; LeGeyt et al., 2017; Roe et al., 2009; Salomon \& Hamilton, 2013). In LeGeyt et al's (2017) study, the participants specifically refer to a power imbalance between them and the professionals involved in their care. This led to feelings of powerlessness and in some cases participants felt coerced into taking medication which further eroded their sense of autonomy and perceived control over the situation. Individuals' autonomy and control was further hampered by the distress they were experiencing at the time, which also rendered them vulnerable and susceptible to coercion (Roe et al. 2009).

Salomon and Hamilton (2013: 162) describes 'transgressions in the therapeutic alliance' which led to decisions to stop taking medication and in some cases the experience was so 'poisoned' the potential for therapeutic alliance was irrevocably damaged. From the initial contact with mainstream mental health services, some participants described the 
pressure they were under to take the medication once they were prescribed (Bjornestad et al., 2017; Katz et al., 2019; Legeyt et al., 2017; Roe et al., 2009; Salomon \& Hamilton, 2013; Tranulis et al., 2011). This came not only from the mental health services but also from the participants' family. In some cases, this coercion was explicit where participants were threatened with rehospitalisation or being forcibly given the medication (Solomon \& Hamilton, 2013; Roe et al., 2009). In Roe et al's (2009) study for example, pressure came from professionals, family and friends and in some cases, participants took medication to maintain the status quo and to please others, especially their families. In addition, one participant stated that access to a rehabilitation service was contingent on their compliance with medication (Roe et al., 2009). Furthermore, in Bjornestad et al's (2017) and LeGeyt et al's (2017) paper, participants talked about the disproportionate emphasis on medication within professional conversations being a challenge which was described as one-sided and biased towards the advantages of taking medication (LeGeyt et al., 2017) or focused on adherence (Bülow et al., 2016). Overall, many participants reported dissatisfaction with their relationship with the mainstream mental health services, and while this dissatisfaction set the scene for their future decisions and actions around discontinuing medication, decisions to stop were not generally made until participants had been taking medication for a period of time.

\section{Theme 2: Discontinuing medication: a thought out process}

The participants' accounts provide evidence that their decision to discontinue medication was an informed thought out process primarily motivated by people's endeavours to exert autonomy and control over their lives and recovery (Bjornestad et al., 2017; Boath et al., Capplman et al., 2015; Fu et al., Gale et al., 2012; Katz et al., 2019; LeGeyt et al., 2017; Roe et al., 2009). There was also a desire to recapture some of the lost sense of control and autonomy that the participant experienced even if the medication was working (LeGeyt et al., 2017). Rather than a sudden reactive action to one issue or event, generally the ultimate decision to discontinue medication was influenced by an appraisal of the risks of becoming unwell, the impact of side effects on the participants' health and well-being and psychological and social consequence of continuing to take medication. In two of the papers this was specifically referred to as a cost benefit analysis (LeGeyt et al., 2017; Cappleman et al., 2015). 
The decision to discontinue medication came about following a period of questioning and personal research to investigate the side effects of medication and evidence to support their effectiveness (Bjornestad et al., 2017; Fu et al., 2019; Gale et al., 2012; LeGeyt et al., 2017). For example, participants in Le Geyt et al's (2017) study spoke of searching the internet and books, and developing confidence over time to seek information from the psychiatrist and more informed others. Based on information received on their 'illness' and the advantages and disadvantages of taking medication, participants began to question the received wisdom of the medical model and biochemical theories, which in turn led them to formulate a personal perspectives or 'hypothesis' on the need to continue taking medication. This included seeking out peer support from other people who had similar experiences as in Gale et al's (2012) study. Personal conceptualisations of mental distress were influential and biomedical explanations of mental illness as a chemical imbalance were often rejected in favour of more holistic perceptions of mental distress (Bjornestad et al., 2017; Bülow et al., 2016; Katz et al., 2019; LeGeyt et al., 2017; Roe et al., 2009; Solomon and Hamilton, 2013; Tranulis et al., 2011). This reappraisal caused participants to seek other ways of managing their mental health difficulties and to source interventions that aligned with personal beliefs about health. For example, in Boath et al's (2004) study, talking to someone about problems was perceived as more helpful, and in Katz et al's (2019) study the participants talked about healing as needing to come from within. Other factors that influenced the participants' decision to discontinue medication are discussed in more detail in theme three.

\section{Theme 3: Factors influencing the decision to discontinue medication}

While the decision to stop taking medication was generally taken over a period of time, there were seven distinct reasons which directly contributed to this decision (table 2). 


\begin{tabular}{|c|c|c|c|c|c|c|c|c|c|c|c|c|c|c|}
\hline & 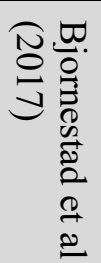 & 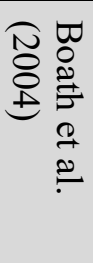 & 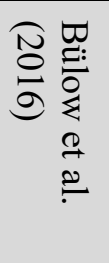 & 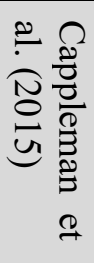 & 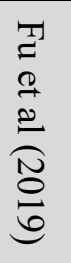 & 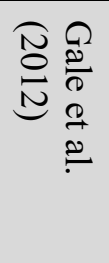 & 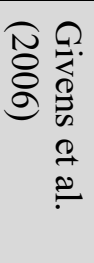 & 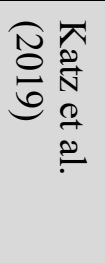 & 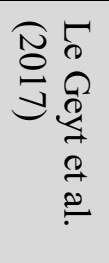 & 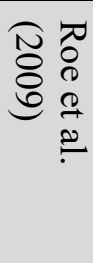 & 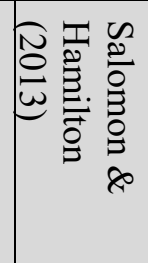 & 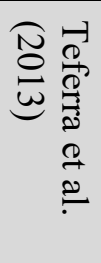 & 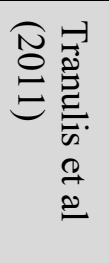 & 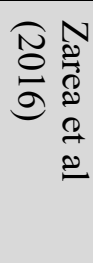 \\
\hline $\begin{array}{l}\text { Physical adverse } \\
\text { effects. }\end{array}$ & $\mathbf{X}$ & $\mathbf{X}$ & $\mathbf{X}$ & $\mathbf{X}$ & $\mathbf{X}$ & & $\bar{X}$ & $\mathbf{X}$ & $\mathbf{X}$ & $\mathbf{X}$ & $\mathbf{X}$ & $\mathbf{X}$ & $\mathbf{X}$ & $\mathbf{X}$ \\
\hline $\begin{array}{l}\text { Psychological } \\
\text { adverse effects. }\end{array}$ & $\mathbf{X}$ & $\mathbf{X}$ & $\mathbf{X}$ & & $\mathbf{X}$ & & $\mathbf{X}$ & $\mathbf{X}$ & $\mathbf{X}$ & $\mathbf{X}$ & & $\mathbf{X}$ & $\mathbf{X}$ & $\mathbf{X}$ \\
\hline $\begin{array}{l}\text { Negative impact on } \\
\text { the participants sense } \\
\text { of self. }\end{array}$ & & & $\mathbf{X}$ & $\mathbf{X}$ & & $\mathbf{X}$ & $\mathbf{X}$ & $\mathbf{X}$ & $\mathbf{X}$ & $\mathbf{X}$ & & & $\mathbf{X}$ & \\
\hline $\begin{array}{l}\text { Relationship with } \\
\text { MH Professional. }\end{array}$ & & & $\mathbf{X}$ & & & & & $\mathbf{X}$ & & $\mathbf{X}$ & $\mathbf{X}$ & & & \\
\hline $\begin{array}{l}\text { Taking medication } \\
\text { perceived as } \\
\text { stigmatising. }\end{array}$ & & & $\mathbf{X}$ & & & & & & $\mathbf{X}$ & $\mathbf{X}$ & & & $\mathbf{X}$ & $\mathbf{X}$ \\
\hline $\begin{array}{l}\text { Persistence or } \\
\text { worsening } \\
\text { 'symptoms' despite } \\
\text { taking medication. }\end{array}$ & $\mathbf{X}$ & $\mathbf{X}$ & & $\mathbf{X}$ & & $\mathbf{X}$ & & $\mathbf{X}$ & & & & & & \\
\hline $\begin{array}{l}\text { Participants did not } \\
\text { believe they needed } \\
\text { to take the medication }\end{array}$ & & $\mathbf{X}$ & $\mathbf{X}$ & & & & & & & & & & $\mathbf{X}$ & $\mathbf{X}$ \\
\hline $\begin{array}{lr}\text { Fear of } & \text { becoming } \\
\text { addicted } & \text { to } \\
\text { medication. } & \end{array}$ & & $\mathbf{X}$ & $\mathbf{X}$ & & & & $\mathbf{X}$ & & & & & & & \\
\hline
\end{tabular}

Table 2. Main factors influencing the decision to discontinue medication 


\section{(1) Physical and psychological adverse effects caused by medication}

In 13 of the studies, the physical side effects experienced was either a critical factor or at least a contributing factor influencing participants' decision to discontinue medication. Weight gain, fatigue, sedation/drowsiness, akathisia and sexual dysfunction were the most commonly cited adverse effects. Psychological adverse effects were also cited as a reason in 11 studies with a diversity of experiences described. Side effects that were visible to others, such as weight gain, akathisia, and involuntary movements were experienced by some as stigmatising, making social interaction challenging (Bülow et al., 2016; Capplemen et al. 2015). Weight gain was also a factor impacting psychological health and body image (Katz et al., 2017). In Katz et al's (2017) study, medications were also perceived as impacting general physical health with all body systems being affected and in Tranulis et al's (2011) study decisions to stop taking medications were attributed to side effects without further detail.

(2) Negative impact of the participants' sense of self

Gale et al. (2012) report that some participants spoke of their inability to tolerate effects that the medication had on their self-identity, with some discontinuing medication in an effort to 're-find' what they called a 'lost sense of self'. In another study, participants report feeling 'unreal" (Le Geyt et al., 2017: 565), living a life where medication had 'erased' their personality. In four studies, the impact of the medication on the participants' sense of self was related to how they experienced emotion, such as blunting of emotions (Boath et al., 2004; Katz et al., 2019; Roe et al. 2009) or the fear that, in the case of Givens et al. (2006), taking an antidepressant would reduce their ability to feel unpleasant experiences. In Katz et al's (2019) study, the participants talked about a loss of their self-identity and in Tranulis et al's (2011) study, a participant longed to return to a premorbid 'normal state'.

\section{(3) Relationships with mental health professionals}

While relationships with professionals has been discussed as influential in the decision making process, impersonal relationships and a lack of dialogue were specifically discussed as a reason for discontinuing medications in four studies (Bülow et al., 2016; Katz et al., 2019; Roe et al., 2009; Salomon \& Hamilton, 2013). In Katz et al's (2019) study, one participant specifically talked about the distrust she felt towards her psychiatrist and the lack of involvement in decision making. In Bülow et al's (2016) study, participants referred to the lack of dialogue between them and the psychiatrist and they felt left out of decisions involving their treatment and what drugs were used. 
(4) Taking medication perceived as stigmatising

Taking medication was also seen as reinforcing a stigmatised identity (Bülow et al. 2016; LeGeyt et al. 2017; Roe et al. 2009; Tranulis et al., 2011; Zarea et al. 2016). Participants reported discontinuing medication in an attempt to reject the 'psychiatric patient' narrative that was assigned to them following their encounters with the mental health services.

(5) Persistence of 'symptoms' despite taking medication

In four studies, the ongoing experiences of 'symptoms' or worsening of 'symptoms' despite adhering to medication prompted people to question the usefulness of medication which in turn led to the decision to stop (Bjornestad et al., 2017; Boath et al., 2004; Cappleman et al., 2015; Gale et al., 2012; Katz et al., 2019).

(6) Participants did not believe they needed to take the medication

In Bülow et al's (2016) study one participant stopped taking medication because of a belief that he did not experience mental distress and therefore did not need medication. Whereas some participants stated that they stopped medication because they had recovered and no longer needed them (Boath et al., 2004; Tranulis et al., 2011; Zarea et al. 2016).

(7) Fears of becoming addicted to the medication

Fears of becoming dependent on the medication was cited as a reason for discontinuing it in three of the included studies (Boath et al., 2004; Bülow et al., 2016; Givens et al., 2006).

\section{Theme 4: Discontinuing medication: experiences of the process}

Cappleman et al (2015), Gale et al (2012) and Katz et al (2019) state that the final decision to stop medication was taken by the participants themselves. In terms of experience of the process, according to Katz et al., (2019) high levels of determination and perseverance were required to reach a successful outcome. Gale et al (2012) describes three main approaches to coming off medication; the participants worked with the doctor to stop, they stopped taking medication and then told their doctor or they stopped and didn't tell anyone. Many of the participants chose not to disclose their plans for fear that they would crumble under the pressure to continue taking them from both professional and family sources (Bülow et al., 2016; Katz et al., 2019; Roe et al., 2009; Salomon \& Hamilon, 2013). In Bjornestad et al's (2017) and Gale et al's (2012) study, some participants discussed the decision with their psychiatrist who was not in favour; however they went against medical advice and stopped anyway. One of the participants in Salomon and Hamilton's (2013) paper describes being 'dropped' by their psychiatrist when they stopped taking the medication. 
Once the decision to stop taking medication was made, participants either stopped abruptly (Roe et al., 2009) or gradually reduced the medication, weaning themselves off the medication over a period of time (Katz et al., 2019; LeGeyt et al., 2017; Roe et al., 2009; Salomon \& Hamilton, 2013). Le Geyt et al (2017) describes two processes that the participants in their study used: 'going solo' or 'forming an alliance'. While some participants were able to forge alliances with either a doctor or significant other (Fu et al., 2019; Gale et al., 2012; Katz et al., 2019; LeGeyt et al., 2017; Roe et al 2009; Salomon \& Hamilton, 2013), forming alliances was perceived as difficult and some participants chose to go solo. In Roe et al's (2009) study, participants reported that they did not seek help or assistance from professionals because they felt that assistance would not be available. Where support was available, especially when it came from a mental health professional, it was described as valuable and validating. For example, one participant described themselves as 'lucky' to have a supportive psychiatrist (Solomon \& Hamilton, 2013). Even when the doctor was unsupportive of the participant's decision, making themselves available to participants during the discontinuation process was perceived as helpful (Roe et al., 2009). In the absence of support from professionals, support from family, friends and peer support was described as helpful (Bjornestad et al., 2017; Boath et al., 2004; Katz et al., 2019; LeGeyt et al., 2017; Roe et al., 2009). Having a belief in the person, supporting their decision, acceptance and kindness were elements specifically mentioned as helpful (Katz et al., 2019).

Across the studies, there was little reference made to the actual medication discontinuation process, with the exception of Bjornestad et al's (2017) and Katz et al's (2019) studies. Participants in these two studies specifically mention researching how to come off medication safely. In Bülow et al's (2016) paper, only one of the nineteen participants had successfully stopped taking medication and in Le Geyt et al's (2017) paper only two of twelve participants were medication free at the time of the interviews, perhaps demonstrating the difficulties associated with the process. In Solomon and Hamilton's (2013) paper, despite participants describing the process as challenging, 21 of the 89 participants were medication free. There were also reference to withdrawal symptoms, which included sleep problems, cognitive changes, relapse, rehospitalisation, breakdown in relationships, suicidal thoughts and violent behaviour (Katz et al., 2019; Salomon \& Hamilton 2013). This prompted many of the participants to recommence medication. 


\section{Theme 5: Outcomes of coming off medications}

Seven of the studies (Bjornestad et al., 2017, Bülow et al., 2016; Cappleman, 2014; Fu et al., 2019; Katz et al., 2019; Roe et al., 2009; Salomon \& Hamilton, 2013) report specific outcomes from the medication discontinuation process. Participants stated that they felt 'normal again' from both a physical and psychological perspective (Bjornestad et al., 2017; Cappleman et al., 2014; Fu et al., 2019; Roe et al., 2009). Others reported having a 'renewed sense of life' and 'increased role engagement' (Solomon and Hamilton 2013). In addition, Roe el al. (2009) details the increased self-confidence participants experienced as a result of relying on their own resources to overcome life's obstacles rather than depending on medication. In Katz et al's (2019) paper, stopping medication enabled some of the participants to disengage from the mental health services which in their view restored a sense of control and allowed them to live a healthy and independent life. One participant in Bülow et al's (2016) study described herself as 'feeling great' once she had stopped taking medication.

\section{Theme 6: Managing mental distress in the absence of medication}

The strategies that participants developed to manage mental distress in the absence of medication, are detailed in four papers (Bülow et al., 2016; Cappleman et al. 2015; LeGeyt et al., 2017; Katz et al., 2019). In LeGeyt et al's (2017) study, as participants became knowledgeable about their medications, they developed a greater understanding of their 'mental illness', the triggers and the role of medication in their lives As their knowledge increased, they proactively began to develop strategies to 'weave a safety net' of support (LeGeyt et al 2017:246). These strategies included keeping a supply of medication to take for a short period, forming alliances with professionals, families and peer support networks, selfmonitoring their triggers and responses and using alternative approaches such as talking therapies. These approaches not only strengthened the chance of the person successfully discontinuing and staying off medication but each strategy strengthened the 'safety net' and compensated for the absence of medications. In Cappleman et al's (2015) study, a range of strategies were incorporated which were designed to have an overall positive impact on wellbeing and subsequently on the participants' mood. These often aligned with participants' personal conceptualisation of wellness which included things like exercising more, eating healthily, talking to friends and meditation. In addition, the participants evaluated these strategies using a cost benefit analysis and continued with those that were effective (Cappleman et al., 2015). Similarly, participants in Katz et al's (2019) study sought tools 
from the religious and spiritual world including prayer and meditation, which were more aligned with their personal values and beliefs. Participant also reported playing music, being creative, writing and poetry (Bülow et al.2016).

\section{Discussion}

To our knowledge this is the first review to synthesize peer reviewed published research literature focused on the lived experiences of people who made a decision to stop taking prescribed medication for their mental health problem. Despite only fourteen studies being included in the review, demonstrating a dearth of literature in this area, the findings do provide us with useful insights into the decision making process and the consequences of the decision to stop taking medication. The qualitative evidence in this review challenges the previously established clinical perspective that individuals with a diagnosis of mental illness lack the insight to make decisions about their medication and do not have the capacity to decide for themselves whether to discontinue treatment (Morant et al., 2016). This review provides evidence that individuals' decision to come off medication is not taken due to lack of insight but rather it is a carefully considered decision embedded within a well thought out process which involves weighing up the benefits and risks of discontinuing medication. Rather than a perceived lack of insight due to the 'mental illness', stopping medication is a decision making process influenced and driven by a variety of personal, health, social and environmental factors. Some of these factors are common to most individuals, such as a desire to live free from adverse side effects, while others are specific to an individuals' personal life goals, such as regaining a sense of self and independence.

While there were exceptions, participants in the studies took the medication initially and were confident that it would work. It is only after discovering that the medications were ineffective, or they experienced side effects, that they decided to stop. This decision was often in the context of being told they had to take medication while also being given limited information about them. For many of the participants, the experiences described were reflective of a mental health service that emphasised symptomology and clinical recovery, rather than functional or personal recovery (Slade et al., 2008). Within these systems participants lacked agency and control (Shepherd et al., 2008) and there were limited opportunities for them to resist the dominant biomedical discourse. This was worsened by the pressures that were exerted on them outside of the mental health services by family and other 
key stakeholders. These experiences are in direct conflict with the current reorientation of the mental health services towards recovery (Department of Health, 2020).

For participants in this review, key recovery orientated practices such as promoting partnership and support for personally defined recovery as outlined by LeBoutillier et al. (2011) were not present. Furthermore, recovery requires a negotiation framework between service users and mental health professionals as well as a requirement to accommodate risk taking (Health Services Executive, 2017), both were absent from the participants' narratives. In fact, partnerships and working relationships as described by LeBoutillier et al (2011) were often compromised when participants wanted to stop take mediation. Recovery orientated approaches advocate for choice and positive risk taking practices (Higgins et al. 2016; Harris et al. 2017). However, the findings from this review highlight that this approach was not always adopted and more research is needed to understand how service users and mental health professionals can work in a more collaborative way to achieve desired outcomes. In the context of no formal guidelines our review also identifies and further confirms the need for formal reduction and coming off medication guidelines for the benefit of service users, health professionals and families.

Given the few studies included in the review, the focus on one time point for data collection and small sample size, larger longitudinal studies that follow service users' experiences of coming off medication across time are required. While adverse effects from medication and poor treatment efficacy have been explored as factors that contribute to people stopping medication, the other factors described in this review are under researched and also require further investigation.

\section{Limitations}

While coming off medication experiences were documented across all 14 papers, it was not the specific focus in all papers meaning that many of the papers lacked detail about this phenomenon. While the majority of studies employed a qualitative design study (table 1), there is a diversity apparent in terms of research design, data collection and data analysis which may compromise the quality of the synthesis presented here. There is also marked heterogeneity in terms of, sample size, gender representation, diagnosis, medication use and age among the participants included. The range of medication experiences described in the review is limited with many medication classifications not included in the selected studies. In 
addition, only peer reviewed papers in English were included in this review, grey literature was not searched for or accessed. Including grey literature and non-English studies may have resulted in more studies being included but was beyond the scope of this review.

\section{Conclusion}

The aim of this review was to present the findings from a systematic review of qualitative studies which explored mental health service users' experiences of coming off medication. Fourteen papers were included in the review and following data extraction and analysis six themes emerged. The findings reveal that for some service users, the focus on prescribing psychotropic medications as a form of treatment for mental distress was not appropriate because they either did not work or were in conflict with service users' health beliefs. Furthermore, the adverse effects were for some, intolerable and necessitated discontinuation. As the mental health services move towards more recovery orientated approaches, decisions about medication use need to be made in the context of partnerships where service users make informed choices. Service users who wish to stop taking medication need to be supported in the context of positive, therapeutic risk where their mental and physical health can be monitored and the likelihood of success increased. In addition, mental health professionals need to move away from ideas of non-compliance and non-adherence towards a focus on partnership, informed decision making and respect for autonomy, even if the decision is not in line with those of the mental health professional.

\section{Funding}

This work was supported by the Health Services Executive (Ireland).

\section{Declaration of interest}

The authors declare no conflict of interest. 


\section{References}

Ascher Svanum, H., Nyhuis, A. W., Stauffer, V., Kinon, B. J., Faries, D. E., Phillips, G. A., Naber, D. (2010). Reasons for discontinuation and continuation of antipsychotics in the treatment of schizophrenia from patient and clinician perspectives. Current Medical Research and Opinion, 26(10), 2403-2410. https://doi.org/10.1185/03007995.2010.515900

Bjornestad, J., Davidson, L., Joa, I., Larsen, T.K., Hegelstad, W.T.V., Langeveld, J., Veseth, M., Melle, I., Johannessen, J.O. \& Bronnick, K. (2017). Antipsychotic treatment: experiences of fully recovered service users. Journal of Mental Health, 26(3), 264-270. https://doi.org/10.1080/09638237.2017.1294735

Bjornestad, J., Lavik, K. O., Davidson, L., Hjeltnes, A., Moltu, C., \& Veseth, M. (2020). Antipsychotic treatment-a systematic literature review and meta-analysis of qualitative studies. Journal of Mental Health, 29(5), 513-523. https://doi.org/10.1080/09638237.2019.1581352

Braun, V., \& Clarke, V. (2006). Using thematic analysis in psychology. Qualitative Research in Psychology, 3(2), 77-101. https://doi.org/10.1191/1478088706qp063oa

Britten, N., Riley, R., \& Morgan, M. (2010). Resisting psychotropic medicines: a synthesis of qualitative studies of medicine-taking. Advances in Psychiatric Treatment, 16(3), 207-218. doi:10.1192/apt.bp.107.005165

Bülow, P., Andersson, G., Denhov, A., \& Topor, A. (2016). Experience of Psychotropic Medication-An Interview Study of Persons with Psychosis. Issues in Mental Health Nursing, 37(11), 820-828. https://doi.org/10.1080/01612840.2016.1224283

Cappleman, R., Smith, I. \& Lobban, F. (2015). Managing bipolar moods without medication: a qualitative investigation. Journal of Affective Disorders, 174(15), 241-249. https://doi.org/10.1016/j.jad.2014.11.055

Chakrabarti S. (2014). What's in a name? Compliance, adherence and concordance in chronic psychiatric disorders. World Journal of Psychiatry, 4(2), 30-36. https://doi.org/10.5498/wjp.v4.i2.30

Chambers, M., McAndrew, S., Nolan, F., Thomas, B., Watts, P., \& Kantaris, X. (2017). Service user involvement in the coproduction of a mental health nursing metric: The Therapeutic Engagement Questionnaire. Health Expectations, 20(5), 871-877. https://doi.org/10.1111/hex.12526

Clark, M. (2015). Co-production in mental health care. Mental Health Review Journal, 20(4), 213-219. http://eprints.lse.ac.uk/64331/

Cooper, R. E., Hanratty, É., Morant, N., \& Moncrieff, J. (2019). Mental health professionals' views and experiences of antipsychotic reduction and discontinuation. PloS one, 14(6), e0218711. https://doi.org/10.1371/journal.pone.0218711 
Department of Health (2020, June 17). Sharing the Vision: A Mental Health Policy for Everyone. $\quad$ https://www.gov.ie/en/publication/2e46f-sharing-the-vision-a-mental-healthpolicy-for-everyone/

Flore, J., Kokanović, R., Callard, F., Broom, A., \& Duff, C. (2019). Unravelling subjectivity, embodied experience and (taking) psychotropic medication. Social Science \& Medicine, 230, 66-73. https://doi.org/10.1016/j.socscimed.2019.04.004

Fu, S., Czajkowski, N., \& Torgalsbøen, A. K. (2019). Cognitive, Work and Social Outcomes in Fully Recovered First-Episode Schizophrenia: On and Off Antipsychotic Medication. Psychiatry Interpersonal and Biological Processes, 82(1), 42-56. https://doi.org/10.1080/00332747.2018.1550735

Gale, C., Baldwin, L., Staples, V., Montague, J., \& Waldram, D. (2012). An exploration of the experience of mental health service users when they decide they would like to change or withdraw from prescribed medications. Journal of Psychiatric and Mental Health Nursing, 19(10), 853-859. https://doi.org/10.1111/j.1365-2850.2011.01860.x

Geyt, G. L., Awenat, Y., Tai, S., \& Haddock, G. (2017). Personal accounts of discontinuing neuroleptic medication for psychosis. Qualitative Health Research, 27(4), 559-572. https://doi.org/10.1177/1049732316634047

Givens, J.L., Datto, C.J., Ruckdeschel, K., Knott, K., Zubritsky, C., Oslin, D.W., Nyshadham, S., Vanguri, P. \& Barg, F.K. (2006). Older patients' aversion to antidepressants: a qualitative study. Journal of General Internal Medicine, 21(2), 146-151. https://doi.org/10.1111/j.15251497.2005.00296.x

Harris, K., Brooks, H., Lythgoe, G., Bee, P., Lovell, K., \& Drake, R. J. (2017). Exploring service users', carers' and professionals' perspectives and experiences of current antipsychotic prescribing: a qualitative study. Chronic Illness, 13(4), 275-287. https://doi.org/10.1177/1742395317694223

Healy, D. (2016). Psychiatric Drugs Explained. Elsevier Health Sciences.

Higgins, A., Doyle, L., Downes, C., Morrissey, J., Costello, P., Brennan, M., \& Nash, M. (2016). There is more to risk and safety planning than dramatic risks: Mental health nurses' risk assessment and safety-management practice. International Journal of Mental Health Nursing, 25(2), 159-170. https://doi.org/10.1111/inm.12180

Health Service Executive (2017) National Framework for Recovery in Mental Health 2018 2020. HSE, Dublin.

Katz, S., Goldblatt, H., Hasson-Ohayon, I., \& Roe, D. (2019). Retrospective accounts of the process of using and discontinuing psychiatric medication. Qualitative Health Research, 29(2), 198-210. https://doi.org/10.1177/1049732318793418

Kreyenbuhl, J., Leith, J., Medoff, D. R., Fang, L., Dickerson, F. B., Brown, C. H., Goldberg, R., Potts, W., Dixon, L. B. (2011). A comparison of adherence to hypoglycemic medications 
between Type 2 diabetes patients with and without serious mental illness. Psychiatry Research, 188(1), 109-114. https://doi.org/10.1016/j.psychres.2011.03.013

Le Boutillier, C., Leamy, M., Bird, V. J., Davidson, L., Williams, J., \& Slade, M. (2011). What does recovery mean in practice? A qualitative analysis of international recoveryoriented practice guidance. Psychiatric Services, 62(12), 1470-1476. https://doi.org/10.1176/appi.ps.001312011

Le Geyt, G., Awenat, Y., Tai, S., \& Haddock, G. (2017). Personal accounts of discontinuing neuroleptic medication for psychosis. Qualitative Health Research, 27(4), 559-572. https://doi.org/10.1177/1049732316634047

Moisan, J., \& Grégoire, J. P. (2010). Patterns of discontinuation of atypical antipsychotics in the province of Québec: a retrospective prescription claims database analysis. Clinical Therapeutics, 32, S21-S31. https://doi.org/10.1016/j.clinthera.2010.01.003

Morant, N., Azam, K., Johnson, S., \& Moncrieff, J. (2018). The least worst option: user experiences of antipsychotic medication and lack of involvement in medication decisions in a UK community sample. Journal of Mental Health, 27(4), 322-328. https://doi.org/10.1080/09638237.2017.1370637

Morant, N., Kaminskiy, E., \& Ramon, S. (2016). Shared decision making for psychiatric medication management: beyond the micro-social. Health Expectations, 19(5), 1002-1014. https://doi.org/10.1111/hex.12392

Moritz, S., Andreou, C., Klingberg, S., Thoering, T., \& Peters, M. J. (2013). Assessment of subjective cognitive and emotional effects of antipsychotic drugs. Effect by defect? Neuropharmacology, 72, 179-186. https://doi.org/10.1016/j.neuropharm.2013.04.039

Morrison, A. P., Hutton, P., Shiers, D., \& Turkington, D. (2012). Antipsychotics: is it time to introduce patient choice?. The British Journal of Psychiatry, 201(2), 83-84. https://doi.org/10.1192/bjp.bp.112.112110

National Institute for Health and Care Excellence, NICE. (2014, March 1). Psychosis and Schizophrenia in Adults: Prevention and Management. (Clinical Guidelines No. 178). United Kingdom: National Institute for Health and Care Excellence. https://www.nice.org.uk/guidance/cg178

National Institute for Health and Care Excellence, NICE. (2020, February 17). Antidepressant Treatment in Adults, NICE Pathways. United Kingdom: National Institute for Health and Care Excellence. http://pathways.nice.org.uk/pathways/depression

Paris, J. (2010). The Use and Misuse of Psychiatric Drugs : An Evidence-Based Critique. John Wiley \& Sons, Incorporated.

Ramachandraiah, C. T., Subramaniam, N., \& Tancer, M. (2009). The story of antipsychotics: Past and present. Indian Journal of Psychiatry, 51(4), 324-326. https://doi.org/10.4103/0019$\underline{5545.58304}$ 
Read, J., Grigoriu, M., Gee, A., Diggle, J., \& Butler, H. (2020). The positive and negative experiences of 342 antidepressant users. Community Mental Health Journal, 1-9. https://doi.org/10.1007/s10597-019-00535-0

Roe, D., Goldblatt, H., Baloush-Klienman, V., Swarbrick, M., \& Davidson, L. (2009). Why and how people decide to stop taking prescribed psychiatric medication: Exploring the subjective process of choice. Psychiatric Rehabilitation Journal, 33, 38-46. https://doi.org/10.2975/33.1.2009.38.46

Salomon, C., \& Hamilton, B. (2013). All Roads Lead to Medication? Qualitative Responses From an Australian First Person Survey of Antipsychotic Discontinuation. Psychiatric Rehabilitation Journal, 36(3), 160-165. https://doi.org/10.1037/prj0000001

Salomon, C., Hamilton, B., \& Elsom, S. (2014). Experiencing antipsychotic discontinuation: results from a survey of Australian consumers. Journal of Psychiatric and Mental Health Nursing, 21(10), 917-923. https://doi.org/10.1111/jpm.12178

Sapra, M., Weiden, P. J., Schooler, N. R., Sunakawa-McMillan, A., Uzenoff, S., \& Burkholder, P. (2014). Reasons for adherence and nonadherence: a pilot study comparing first-and multi-episode schizophrenia patients. Clinical Schizophrenia \& Related Psychoses, 7(4), 199-206. https://doi.org/10.3371/CSRP.SAWE.020813

Shepherd, G., Boardman, J., \& Slade, M. (2008). Making Recovery a Reality. Sainsbury Centre for Mental Health.

Slade, M., Amering, M., \& Oades, L. (2008). Recovery: an international $\begin{array}{llr}\text { perspective. Epidemiology asychiatric } \quad \text { Sciences, } 17(2), & 128-137 .\end{array}$ https://doi.org/10.1017/S1121189X00002827

Sparks, J.A. (2016). White paper: Efficacy of psychiatric drugs. Ethical Human Psychology and Psychiatry 18(1), 20-28. http://dx.doi.org/10.1891/1559-4343.18.1.20

Steingard, S. (2019). Clinical implications of the drug-centered approach. In S. Steingard (Ed.), Critical Psychiatry: Controversies and Clinical

Implications (pp. 113-135). Springer.

Teferra, S., Hanlon, C., Beyero, T., Jacobsson, L., \& Shibre, T. (2013). Perspectives on reasons for non-adherence to medication in persons with schizophrenia in Ethiopia: a qualitative study of patients, caregivers and health workers. BMC psychiatry, 13(1), 1-9. https://doi.org/10.1186/1471-244X-13-168

Thomas, J., \& Harden, A. (2008). Methods for the thematic synthesis of qualitative research in systematic reviews. BMC Medical Research Methodology, 8(1), 1-10.

https://doi.org/10.1186/1471-2288-8-45

Thompson, J., Stansfeld, J. L., Cooper, R. E., Morant, N., Crellin, N. E., \& Moncrieff, J. (2020). Experiences of taking neuroleptic medication and impacts on symptoms, sense of self and agency: a systematic review and thematic synthesis of qualitative data. Social psychiatry and Psychiatric Epidemiology, 55(2), 151-164. https://doi.org/10.1007/s00127-019-01819-2 
Tranulis, C., Goff, D., Henderson, D. C., \& Freudenreich, O. (2011). Becoming adherent to antipsychotics: a qualitative study of treatment-experienced schizophrenia patients. Psychiatric Services, 62(8), 888-892. https://doi.org/10.1176/ps.62.8.pss6208_0888

Verdoux, H., Pambrun, E., Tournier, M., Bezin, J., \& Pariente, A. (2017). Risk of discontinuation of antipsychotic long-acting injections vs. oral antipsychotics in real-life prescribing practice: a community-based study. Acta Psychiatrica Scandinavica, 135(5), 429438. https://doi.org/10.1111/acps.12722

Walter, H. (2013). The third wave of biological psychiatry. Frontiers in Psychology, 4 (582), 1-8. https://doi.org/10.3389/fpsyg.2013.00582

Wunderink, L. (2019). Personalizing antipsychotic treatment: evidence and thoughts on individualized tailoring of antipsychotic dosage in the treatment of psychotic disorders. Therapeutic Advances in Psychopharmacology. https://doi.org/10.1177/2045125319836566

Zarea, K., Fereidooni-Moghadam, M., \& Hakim, A. (2016). Adherence to medication regimen in patients with severe and chronic psychiatric disorders: A qualitative study. Issues in Mental Health Nursing, 37(11), 868-874. https://doi.org/10.1080/01612840.2016.1239147 